$\$=$

\title{
Advanced maternal age and late pregnancy outcome at Omdurman New Hospital in Sudan
}

\author{
Khalid Yassin M. Ahmed ${ }^{1 *}$, Shireen Abdulla Ahmed ${ }^{2}$, Siddig Omer Handady ${ }^{3}$, \\ Awad Ali M. Alawad ${ }^{4}$, Sulafa Hatim H. Ali \\ ${ }^{I}$ Department of Obstetrics and Gynecology, Al Neelain University, Khartoum, Sudan \\ ${ }^{2}$ Department of Obstetrics and Gynecology, Omdurman New Hospital, Khartoum, Sudan \\ ${ }^{3}$ Department of Obstetrics and Gynecology, Imperial Hospital, Khartoum, Sudan \\ ${ }^{4}$ Department of Surgery, University of Medical Sciences and Technology, Khartoum, Sudan \\ ${ }^{5}$ Faculty of Medicine, University of Gezira, Wad Medani, Sudan \\ *Corresponding author E-mail: Khalidym@hotmail.com
}

\begin{abstract}
Background: Advanced Maternal age has a 2-3 fold higher risk of pregnancy-related death than women in their twenties, and the risk is even more dramatic for women 40 years and older.

Objective: The overall aim was to examine the association between maternal age and a wide range of adverse pregnancy outcomes.

Methodology: This is a case-control hospital-based study carried out at Omdurman New Hospital in Khartoum State, Sudan in the period from July 2013 to January 2014. Three hundred women presented in labour were enrolled in this study. One hundred women at 40 years age or more presented after 24th week of pregnancy represented the study group. Two hundred women between 18-39-year age; same gestational ages were selected as the control group.

Results: The mean of age was $42 \pm 2$ STD (min 40 and max 45 years) among the case group, and it was $27 \pm 2$ STD (min 20 and max 39 years) among the case group. Women aged 40 years or older had increased percentages of gestational hypertension (23.0\% vs. 13.5\%; $\mathrm{p}=0.03)$ and diabetes in pregnancy $(8.0 \%$ vs. $4.0 \% ; \mathrm{p}=0.03)$ compared with women younger than 40 years. There were significant differences between the two age groups in, antepartum hemorrhage, preterm labor, and premature rupture of membranes, perinatal death, and postpartum hemorrhage. Vaginal delivery in case group was $53(53 \%)$ against $127(63.5 \%)$ in control group, caesarean section found in $47(47 \%)$ of case group against $36.5 \%$ of control group, instrumental found in one patient (1\%) of case group and it was absent in control group.

Conclusion: Advanced maternal age is a risk factor for premature rupture of membranes, preterm labour, pre-eclampsia, stillbirth, gestational diabetes mellitus, placenta previa, abruptio placentae and cesarean section, but not for small for gestational age, gestational hypertension, or large for gestational age.
\end{abstract}

Keywords: Advance Maternal Age; Fetal Outcome.

\section{Introduction}

There is no universal definition of advanced reproductive age in women, in part because the effects of increasing age occur as a continuum, rather than as a threshold effect. Fertility clearly declines with advancing age, especially after the mid-30s, and women who conceive are at greater risk of pregnancy complications (Luke \& Brown 2007). However, studies have generally shown that women over 45 years of age or over 50 years of age have good pregnancy outcomes and are able to cope with the physical and emotional stresses of pregnancy and parenting (Steiner \& Paulson 2007). The prevalence of medical and surgical illnesses, such as cancer; cardiovascular, renal, and autoimmune disease; and obesity increases with advancing age. For this reason, women $\geq 35$ years of age can expect to experience two- to three-fold higher rates of hospitalization, cesarean delivery, and pregnancyrelated complications than their younger counterparts(ClearyGoldman et al. 2005).
Women between 35 - 39 years old have three-foldrisk of pregnancy-relateddeath than women in their twenties, and the risk is even more dramatic for women aged 40 years and older (Balasch \& Gratacos 2012).Furthermore, gravidas of advanced age are at a higher risk for stillbirth and perinatal morbidity and mortality. At delivery, increased maternal age is associated with an increased rate of malpresentation and represents an independent odds ratio for cesarean section. Owing to these facts, obstetric management in the older gravida needs to be adapted in order to manage the possible complications (Franz \& Husslein 2010). The aim of this study was to examine the association between maternal age and a wide range of adverse pregnancy outcomes after adjustment for confounding factors in maternal characteristics and obstetric history.

\section{Material and methods}

These were a prospective case control and hospital-basedstudy carried out at women attending in labour after 24-weekgestational age at Omdurman Knew hospital in Sudan. Three hundred women 
were enrolled in this study. One hundred women at 40 years age or more after 24th week of pregnancy represented the study group.Two hundred women between 18-39-yearage; same gestational ages were selected as the control group. Participants completed a questionnaire on their age, racial origin, method of conception (spontaneous or assisted), history of chronic hypertension, history of Type 1 or Type 2 diabetes mellitus and obstetric history, including the outcome of each previous pregnancy. Outcome measures included, stillbirth, pre-eclampsia, gestational hypertension, gestational diabetes mellitus (GDM), spontaneous and iatrogenic preterm delivery before 34weeks' gestation, delivery of a small for gestational age (SGA) or large for gestational age (LGA) neonate and delivery byemergency cesarean section. We excluded pregnancies with uncertain age, less than 18 years, uncertain date and less than 24 weeks gestational age (GA).

The data was analyzed by using Statistical Package of Social Science (SPSS) version 20.Obtained results presented in tables and figure. The confidence interval of $95 \%$ and the P. value equal to 0.05 was used in this study. Mean, median and mode was used to explain demographic variables. Ethical clearance and approval for conducting this research was obtained from the general manager of the hospital and informed written consent was obtained from every respondent who agreed to participate in the study. Of course, the respondents informed that the study is not associated with experimental or therapeutic intervention while information was collected from her.

\section{Results}

One hundred of women aged 40 years and older (response study group) and two hundred of women aged 18-35 years (response control group) were included in this study. Table 1 shows the maternal characteristics of two groups. The mean of age was $42 \pm 2$ Std (min 40 and max 45 years) among the case group, and it was $27 \pm 2$ Std (min 20 and max 39 years) among the case group. The percentage of educated women $(61 \%$ vs. $84.0 \%$; $\mathrm{p}=0.017)$ was significantly higher in the women aged 18-35 years compared with older age group. Induced pregnancy was higher in older women compared to younger women not significantly (59.0 vs. $24.0 \% ; \mathrm{p}=0.07)$. Women aged 40 years or older had increased percentages of gestational hypertension $(23.0 \%$ vs. $13.5 \%$; $\mathrm{p}=0.03)$ and diabetes in pregnancy $(8.0 \%$ vs. $4.0 \% ; \mathrm{p}=0.03) \mathrm{com}-$ pared with women younger than 40 years.

There were significant differences between the two groups in, antepartum hemorrhage, preterm labor, premature rupture of membranes (PROM), perinatal death, congenital anomaly, neonatal intensive care unit (NICU) admission and postpartum hemorrhage. Vaginal delivery in case group was $53(53 \%)$ against 127 $(63.5 \%)$ in control group, caesarean section found in $47(47 \%)$ of case group against $36.5 \%$ of control group, instrumental found in one patient $(1 \%)$ of case group and it was absent in control group ,for more details see table 2

\section{Discussion}

The current study showed that women aged 40 years or older, their pregnancy were induced more than younger women. These findings are consistent with other study done by Ziadeh et al, who obtained same result(Ziadeh 2002).

It is not surprising to notice that, the finding of current study revealed that the women aged 40 years or older are at risk for some pregnancy outcomes such as diabetes in pregnancy, hypertension in pregnancy, and cesarean delivery. Our result was comparable to other studies, which obtained same finding (Chan \& Lao 2008, Gilbert et al. 1999). This was supported by the findings from Danielsen et al(Usta \& Nassar 2008).However, the prevalence of diabetes and hypertension are increased by age, and related to vascular endothelial damage that occurs with aging. Pancreatic B-cell function and insulin sensitivity fall with age, it is shown that about $16 \%$ of elderly pregnant women have an abnormal glucose toler- ance test (Bayrampour et al. 2012).Moreover,our result showed that, PPROM, PPH, Placenta previa and abruption placentae were found higher in older women.Additionally, there was strong association between these complications and age. Gilbert WM, et al ${ }^{(9)}$ reported that, the prevalence of placental problems, such as abruptio placentae and placenta previa, is higher among older women, which support the current study. One the same point of view this finding has previously reported in earlier studies(Suzuki \& Miyake 2008). It could be explained by the effect of advanced age and vascular damages and is also associated with chronic hypertensive disorders in this group of women (Giri et al. 2013). In contrast to the current study, other study revealed that, postpartum hemorrhage and PPROM have no significant association(Gribble et al. 2014). The discrepancy between our study and this study can be explained by multiple factors such as in our study, the high incidence of grand multiparous might be main reasonfor increase the postpartum hemorrhage.

The present study showed that preterm labour was found higher in older women (20\% against $14 \%$ ) but showed no significant association (P 0.122). Again our results are correlated with Goldman, et al(Giri et al. 2013), who concluded that was not a statistically significant association between maternal older age and increased risk for preterm labor and PROM.

Neonatal intensive care unit admission was more among older women versus younger ones. It may be due to higher rates of LBW, SGA, and preterm delivery in this group. However, this finding was supported by another study (Tandberg et al. 2015).In the current study, older women showed higher fetal death and congenital anomalies versus younger women $(15 \%$ stillbirth against $1.5 \%$ with $\mathrm{P}$ value $0.000,16 \%$ congenital anomalies against $4 \%$ with $\mathrm{P}$ value0. 006).). Most large studies worldwide have reported similar findings and concluded that, older women are at significantly increased risk of stillbirth compared with younger women, with relative risks of 1.2 to 4.5 (Balasch \& Gratacos 2012). The risk of having a child with a congenital anomaly may increase with increasing maternal age (Steiner \& Paulson 2007). LBW and macrosomia showed a little higher percentage in the older women compared to younger women; they were $24 \%$ versus $10 \%$ and $20 \%$ versus $12 \%$ respectively, but $\mathrm{p}$ value showed no statistical significance $(0.200)$. Brabin reported in their study in 2008 that,after adjusting for these factors, older age was associated with a significantly higher risk of LBW(Chan \& Lao 2008). Other studies reported that, mothers of older than 40 faced the second higher risk of having low birth weight after younger teenagers (Cleary-Goldman et al. 2005).

The results of this study demonstrate that advanced maternal age, is associated with increased risk for a wide range of adverse pregnancy outcomes, including, PROM, Placenta previa, Abruption placenta and Cesarean section, stillbirth, but not gestational hypertension, spontaneous preterm delivery or LGA. These findings are of particular interest to both the women themselves and healthcare professionals because of the rising trend to delayed childbearing secondary to improving access to education, career opportunities, and contraception and assisted reproductive techniques.

\section{Conclusion}

Pregnancy outcome of women who passed their dates associated with adverse maternal morbidity, perinatal morbidity and mortality (i.e., stillbirths plus early neonatal deaths). Maternal and neonatal morbidity is related, in part, to complications from PROM, preterm delivery, pre-eclampsia, SGA, GDM and Cesarean section 
Table 1: Shows the Nonparametric Correlation between Study and Control Group Regarding Demographic Data

\begin{tabular}{|c|c|c|c|c|c|}
\hline & \multicolumn{2}{|c|}{ Study group } & \multicolumn{2}{|c|}{ Control group } & \multirow{2}{*}{$\mathrm{P}$} \\
\hline & Count & $\%$ & Count & $\%$ & \\
\hline \multicolumn{6}{|l|}{ Education Level } \\
\hline Less than high school & 39 & $39.0 \%$ & 32 & $16.0 \%$ & \multirow{3}{*}{0.017} \\
\hline High school or more & 61 & $61.0 \%$ & 168 & $84.0 \%$ & \\
\hline Total & 100 & $100.0 \%$ & 200 & $100.0 \%$ & \\
\hline \multicolumn{6}{|l|}{ Parity } \\
\hline Primigravida & 08 & $08.0 \%$ & 46 & $23.0 \%$ & \multirow{4}{*}{$0.00 *$} \\
\hline Multipara & 52 & $52.0 \%$ & 144 & $72.0 \%$ & \\
\hline Grandmultipara & 40 & $40.0 \%$ & 10 & $05.0 \%$ & \\
\hline Total & 100 & $100.0 \%$ & 200 & $100.0 \%$ & \\
\hline \multicolumn{6}{|l|}{ Medical disorder } \\
\hline Deep vein thrombosis & 08 & $08.0 \%$ & 10 & $05.0 \%$ & \multirow{8}{*}{$0.03^{*}$} \\
\hline Essential hypertension & $\begin{array}{l}00 \\
18\end{array}$ & $18.0 \%$ & 00 & $00.0 \%$ & \\
\hline Pregnancy induced & 23 & $23.0 \%$ & 27 & $13.5 \%$ & \\
\hline hypertension & 01 & $01.0 \%$ & 10 & $05.0 \%$ & \\
\hline Pre eclamsia & 08 & $08.0 \%$ & 00 & $00.0 \%$ & \\
\hline DM & 08 & $08.0 \%$ & 08 & $04.0 \%$ & \\
\hline $\begin{array}{l}\text { GDM } \\
\text { None }\end{array}$ & 34 & $34.0 \%$ & 145 & $72.5 \%$ & \\
\hline $\begin{array}{l}\text { None } \\
\text { Total }\end{array}$ & 100 & $100.0 \%$ & 200 & $100.0 \%$ & \\
\hline Status of pregnancy & 41 & $41.0 \%$ & 152 & $76.0 \%$ & \multirow{3}{*}{0.078} \\
\hline Spontaneous & 59 & $59.0 \%$ & 48 & $24.0 \%$ & \\
\hline $\begin{array}{l}\text { Induced } \\
\text { Total }\end{array}$ & 100 & $100.0 \%$ & 200 & $100.0 \%$ & \\
\hline
\end{tabular}

*StatistiCAlly SignifiCANT AT 0.05 LEVEL

Table 2: Shows the Nonparametric Correlation between Study and Control Group Regarding Pregnancy Outcome

\begin{tabular}{|c|c|c|c|c|c|}
\hline & \multicolumn{2}{|c|}{ Study group } & \multicolumn{2}{|c|}{ Control group } & \multirow{2}{*}{$\mathrm{P}$} \\
\hline & Count & $\%$ & Count & $\%$ & \\
\hline \multicolumn{6}{|l|}{ Mode of delivery } \\
\hline Spontaneous vaginal & & & & & \multirow{7}{*}{$0.000 *$} \\
\hline delivery & 52 & $52.0 \%$ & 127 & $63.5 \%$ & \\
\hline Induced vaginal deliv- & 01 & $01.0 \%$ & 00 & $00.0 \%$ & \\
\hline ery & 47 & $47.0 \%$ & 73 & $36.5 \%$ & \\
\hline Cesarean section & 100 & $100.0 \%$ & 200 & $100.0 \%$ & \\
\hline \multirow{2}{*}{\multicolumn{5}{|c|}{ Total }} & \\
\hline & & & & & \\
\hline PROM & 20 & $20.0 \%$ & 16 & & \multirow{7}{*}{$0.04 *$} \\
\hline Preterm labour & 20 & $\begin{array}{l}20.0 \% \\
20.0 \%\end{array}$ & $\begin{array}{l}10 \\
28\end{array}$ & $\begin{array}{l}08.0 \% \\
14.0 \%\end{array}$ & \\
\hline Post-partum hemor- & 18 & $18.0 \%$ & 01 & $00.5 \%$ & \\
\hline rhage & 09 & $09.0 \%$ & 05 & $02.5 \%$ & \\
\hline Placenta previa & 08 & $08.0 \%$ & 04 & $02.0 \%$ & \\
\hline Abruption placenta & 25 & $25.0 \%$ & 146 & $73.0 \%$ & \\
\hline $\begin{array}{l}\text { No complication } \\
\text { Total }\end{array}$ & 100 & $100.0 \%$ & 200 & $100.0 \%$ & \\
\hline \multicolumn{6}{|l|}{ Congenital anomaly } \\
\hline Yes & 16 & $16.0 \%$ & 08 & $04.0 \%$ & \multirow{3}{*}{$0.006^{*}$} \\
\hline No & 84 & $84.0 \%$ & 192 & $96.0 \%$ & \\
\hline Total & 100 & $100.0 \%$ & 200 & $100.0 \%$ & \\
\hline \multicolumn{6}{|l|}{ Fetal outcome } \\
\hline Alive & 85 & $85.0 \%$ & 197 & $98.5 \%$ & \multirow{4}{*}{$0.00 *$} \\
\hline FSB & 06 & $06.0 \%$ & 01 & $00.5 \%$ & \\
\hline MSB & 09 & $09.0 \%$ & 02 & $01.0 \%$ & \\
\hline Total & 100 & $100.0 \%$ & 200 & $100.0 \%$ & \\
\hline \multicolumn{6}{|l|}{ Low birth weight } \\
\hline Yes & 24 & $24.0 \%$ & 20 & $10.0 \%$ & \multirow{3}{*}{0.142} \\
\hline No & 76 & $76.0 \%$ & 180 & $90.0 \%$ & \\
\hline Total & 100 & $100.0 \%$ & 200 & $100.0 \%$ & \\
\hline \multicolumn{6}{|l|}{ Macrosomia } \\
\hline Yes & 20 & $20.0 \%$ & 21 & $10.5 \%$ & \multirow{3}{*}{0.20} \\
\hline No & 80 & $80.0 \%$ & 179 & $89.5 \%$ & \\
\hline Total & 100 & $100.0 \%$ & 200 & $100.0 \%$ & \\
\hline NICU admission & 18 & $18.0 \%$ & 24 & $12.0 \%$ & \multirow{3}{*}{$0.01 *$} \\
\hline Yes & 82 & $82.0 \%$ & 176 & $88.0 \%$ & \\
\hline No & 100 & $100.0 \%$ & 200 & $100.0 \%$ & \\
\hline
\end{tabular}

*STATISTICALLY SigNIFICANT AT 0.05 LEVEL

\section{References}

[1] Balasch J \& Gratacos E (2012): Delayed childbearing: effects on fertility and the outcome of pregnancy. Curr Opin Obstet Gynecol 24, 187-193.http://dx.doi.org/10.1097/GCO.0b013e3283517908.

[2] Bayrampour H, Heaman M, Duncan KA \& Tough S (2012): Advanced maternal age and risk perception: a qualitative study. $B M C$ Pregnancy Childbirth 12, 100.http://dx.doi.org/10.1186/1471-239312-100.

[3] Chan BC \& Lao TT (2008): Effect of parity and advanced maternal age on obstetric outcome. Int J Gynaecol Obstet 102, $237-$ 241.http://dx.doi.org/10.1016/j.ijgo.2008.05.004.

[4] Cleary-Goldman J, Malone FD, Vidaver J, Ball RH, Nyberg DA, Comstock CH, Saade GR, Eddleman KA, Klugman S, Dugoff L, Timor-Tritsch IE, Craigo SD, Carr SR, Wolfe HM, Bianchi DW, D'Alton M \& Consortium F (2005): Impact of maternal age on obstetric outcome. Obstet Gynecol 105, 983 990.http://dx.doi.org/10.1097/01.AOG.0000158118.75532.51.

[5] Franz MB \& Husslein PW (2010): Obstetrical management of the older gravida. Womens Health (Lond Engl) 6, 463468.http://dx.doi.org/10.2217/whe.10.26.

[6] Gilbert WM, Nesbitt TS \& Danielsen B (1999): Childbearing beyond age 40: pregnancy outcome in 24,032 cases. Obstet Gynecol 93, 914.http://dx.doi.org/10.1016/S0029-7844(98)00382-2.

[7] Giri A, Srivastav VR, Suwal A \& Tuladhar AS (2013): Advanced maternal age and obstetric outcome. Nepal Med Coll J 15, 87-90.

[8] Gribble KE, Jarvis G, Bock M \& Mark Welch DB (2014): Maternal caloric restriction partially rescues the deleterious effects of advanced maternal age on offspring. Aging Cell 13, 623 630.http://dx.doi.org/10.1111/acel.12217.

[9] Luke B \& Brown MB (2007): Contemporary risks of maternal morbidity and adverse outcomes with increasing maternal age and $\begin{array}{llll}\text { plurality. } & \text { Fertil } & \text { Steril } & 88,\end{array}$ 293.http://dx.doi.org/10.1016/j.fertnstert.2006.11.008.

[10]Steiner AZ \& Paulson RJ (2007): Motherhood after age 50: an evaluation of parenting stress and physical functioning. Fertil Steril 87, 1327-1332.http://dx.doi.org/10.1016/j.fertnstert.2006.11.074.

[11]Suzuki S \& Miyake H (2008): Obstetric outcomes in nulliparous women aged 35 and over with singleton pregnancies conceived by in vitro fertilization. Arch Gynecol Obstet 277, 225227.http://dx.doi.org/10.1007/s00404-007-0461-y.

[12] Tandberg A, Klungsoyr K, Romundstad LB \& Skjaerven R (2015): Pre-eclampsia and assisted reproductive technologies: consequences of advanced maternal age, interbirth intervals, new partner and smoking habits. BJOG 122, 915-922.http://dx.doi.org/10.1111/14710528.13051 .

[13] Usta IM \& Nassar AH (2008): Advanced maternal age. Part I: obstetric complications. Am $J$ Perinatol 25, 521534.http://dx.doi.org/10.1055/s-0028-1085620.

[14]Ziadeh SM (2002): Maternal and perinatal outcome in nulliparous women aged 35 and older. GynecolObstet Invest 54, 610.http://dx.doi.org/10.1159/000064689. 